\title{
Examining the Effects of Tourism Impacts on Satisfaction with Tourism between Native and Non-native Residents
}

Article in International Journal of Tourism Research • May 2014

DOI: $10.1002 /$ jtr.1922

CITATIONS

4

3 authors, including:

\section{Deborah Kerstetter}

Pennsylvania State University

104 PUBLICATIONS 2,689 CITATIONS

SEE PROFILE
READS

80

Some of the authors of this publication are also working on these related projects:

Project MS thesis View project

Project Leisure Constraints View project 


\title{
Examining the Effects of Tourism Impacts on Satisfaction with Tourism between Native and Non-native Residents
}

\author{
HUI 'JIMMY' XIE ${ }^{1, \star}$, JIGANG BAO ${ }^{2}$ and DEBORAH L. KERSTETTER ${ }^{3}$ \\ ${ }^{1}$ Department of Recreation and Tourism Management, California State University, Northridge, Northridge, CA, USA \\ ${ }^{2}$ School of Tourism Management, Sun Yat-Sen University, Guangzhou, China \\ ${ }^{3}$ Department of Recreation, Park, and Tourism Management, The Pennsylvania State University, University Park, PA, USA
}

\begin{abstract}
SUMMARY
By using a sample of residents in Huangshan, China, this study examined whether tourism impacts affect the overall satisfaction of native and non-native residents in different ways. Results of multiple-group analysis revealed significant differences between the two groups regarding the effects of environmental degradation and loss of traditions and norms. Specifically, environmental degradation negatively affects non-native residents' satisfaction but does not affect native residents' satisfaction. Loss of traditions and norms has a negative effect on native residents' satisfaction but has a positive effect on non-native residents' satisfaction. Theoretical and practical implications are discussed. Copyright (C) 2012 John Wiley \& Sons, Ltd.
\end{abstract}

Received 17 December 2011; revised 17 September 2012; accepted 21 September 2012

Keywords: tourism impact; satisfaction; residents; China.

\section{INTRODUCTION}

Many communities embrace tourism as a tool for economic development (Lankford and Howard, 1994; Andereck et al., 2005), despite the fact that there are documented negative impacts of tourism development such as increased living costs, environmental pollution and loss of traditional culture (Mok et al., 1991; Andereck, 1995; Haralambopoulos and Pizam, 1996). Researchers have found that perceptions of impacts will affect residents' satisfaction with and support for tourism (e.g., Perdue et al., 1987; Cottrell et al., 2005; Dyer et al., 2007; Shen and Cottrell, 2008). Missing from existing research is a differentiation between native-born (from here on referred to as 'native') and non-native-born (from here on referred to as 'non-native') residents.

To maintain harmony in a community, tourism planners must ensure the satisfaction of natives and non-natives (Byrd et al., 2009; Spencer, 2010). This may be difficult, however, as both groups may have varying concerns and expectations for tourism development due to their different cultural backgrounds and place attachment (Sheldon and Var, 1984). Their level of satisfaction also may be affected differently by their perceptions of tourism impacts. Unfortunately, there is limited knowledge about the potential differences between the two groups in terms of the impact-satisfaction relationship. Thus, the objective of this study is to examine whether natives and non-natives differ from each other in terms of the impact-satisfaction relationship.

Huangshan, China, was chosen as the research site for this study for two primary reasons. First, China has witnessed a surge of immigration across regions in the past two decades

* Correspondence to: Hui 'Jimmy' Xie, Assistant Professor, Department of Recreation and Tourism Management, California State University, Northridge, 18111 Nordhoff Street, Northridge, CA 91330-8269, USA

E-mail: jimmy.xie@csun.edu due to the implementation of its market economy policy (Cai and Wang, 2008). Second, as a famous destination in China, Huangshan attracts immigrants from other areas in China. Accordingly, this study chose to examine four tourism impacts that are typical in Huangshan or other communities, which are economic development, environmental degradation, loss of traditions and norms and sociocultural development (Liu and Var, 1986; Lu, 1996; Dyer et al., 2003).

\section{NATIVES VERSUS NON-NATIVES: GENERIC DIFFERENCES}

\section{Cultural difference and acculturation}

Natives and non-natives were born and raised in different cultures. According to Hofstede (2001), culture is 'the collective programming of the mind that distinguishes the members of one group or category of people from another' (p. 9). Different cultures have different social customs, norms and, more importantly, value systems and ways of thinking (Altman and Chemers, 1984; Hofstede, 2001). After immigration, non-natives may adjust their original cultural and value system through interaction with local society. This adjustment process is called, 'acculturation' (Berry et al., 1986), which is defined as 'the changes in the immigrants' cultural beliefs and values toward those of the host society' (Rogler, 1994, p. 706). Acculturation is a long and dynamic process (Phinney, 1990) and may result in non-natives' acceptance or rejection of the local culture as well as their own culture (Berry, 1990, 1997). Regardless of the outcomes of acculturation, non-natives usually are different from natives in terms of culture and values, especially when immigration occurs after young adulthood (Zimmermann et al., 2007). As a result, natives and non-natives may assign different levels of importance to tourism impacts when evaluating local 
tourism development (i.e., culture and value affect individuals' evaluation; Smith and Bond, 1999; Aaker and Schmitt, 2001).

\section{Place attachment}

Natives and non-natives may have different levels of attachment to the local community (Low and Altman, 1992). Place attachment is defined as an emotional, cognitive and functional bond with a place (Williams et al., 1992). Since natives were born and raised in the local community, they are expected to be more attached to the local community than non-natives (Sheldon and Var, 1984; Um and Crompton, 1987; Hernández et al., 2007). As a result, natives should attach particular importance to the tourism impacts that are likely to influence the things they feel attached to (e.g., physical environment and culture).

From the previous discussion regarding the generic differences between natives and non-natives, the following hypothesis is proposed:

H1: Natives and non-natives will differ from each other in terms of the relationship between perceived tourism impacts and overall satisfaction with tourism.

\section{NATIVES VERSUS NON-NATIVES: DIFFERENCES IN RESPONSE TO SPECIFIC TOURISM IMPACTS}

\section{Economic development}

Economic development has been the primary justification used for tourism development in many communities (Lankford and Howard, 1994; Andereck and Vogt, 2000). Theoretically, tourism brings local communities positive economic impacts such as increased employment opportunities, more business investment and increased personal income (e.g., Pizam and Pokela, 1985; Liu and Var, 1986; Perdue et al., 1990; Johnson et al., 1994). These positive impacts are expected to result in more positive attitude toward tourism development. Yoon et al. (2001), Gursoy and Rutherford (2004) and Dyer et al. (2007) found that economic development had a positive effect on residents' support for tourism. And Shen and Cottrell (2008) reported a positive relationship between perceived economic development and residents' satisfaction with tourism in several communities in China. However, a positive relationship was not evidenced in a community in the Netherlands (Cottrell et al., 2005), indicating that economic development may not be salient to some residents.

Natives and non-natives may differ with respect to the concern with economic development. Non-native residents may have a smaller social network and feel more psychologically insecure than natives (Suh and Lee, 2006). With financial security, however, psychological insecurity may be offset (Catalano, 1991; Rocha et al., 2006). Therefore, non-natives may be more concerned with the economic development and benefits from tourism development. From this reasoning, the following hypothesis is proposed:

Hla: Perceived economic development will have a positive effect on residents' overall satisfaction with tourism, with the effect being stronger for non-natives than for natives.

\section{Environmental degradation}

Environmental degradation negatively impacts tourism development. Without proper management, tourism can cause undesirable impacts such as air, water and soil pollution, destruction of ecological habitat and increased noise levels (Andereck, 1995). Researchers have documented a negative relationship between perceived environmental degradation and residents' overall satisfaction with or support for tourism (e.g., Chen and Hsu, 2001; Yoon et al., 2001; Cottrell et al., 2005; Shen and Cottrell, 2008). However, the magnitude of this negative relationship is likely to vary between natives and non-natives because the two groups may have different levels of concerns with the degradation of local environment. Researchers have found that residents' concern with environmental degradation is positively related to their place attachment (e.g., Devine-Wright and Howes, 2010; Scannell and Gifford, 2010). Since natives usually are more attached to the physical environment of the local community (Sheldon and Var, 1984; Hernández et al., 2007), they should be more concerned with the environmental degradation than nonnatives. As a result, environmental degradation should have a stronger effect on the overall satisfaction for the natives than for the non-natives. This hypothesis is summarized as follows:

$H 1 b$ : Perceived environmental degradation will have a negative effect on residents' overall satisfaction with tourism, with the effect being stronger for natives than for non-natives.

\section{Loss of traditions and norms}

In addition to environmental degradation, tourism could lead to loss of local traditions and norms. Previous studies have found that tourism development may result in disappearance of traditional values, degradation of morality, increased crime and decreased interpersonal trust in a community (Doğan, 1989; Kousis, 1989; Mok et al., 1991; Lu, 1996; Tosun, 2002; Dyer et al., 2003). Loss of local traditions and norms was found to have a negative effect on residents' overall satisfaction with or support for tourism (e.g., Chen and Hsu, 2001; Yoon et al., 2001; Cottrell et al., 2005; Shen and Cottrell, 2008). However, this negative relationship has been challenged. For example, Gursoy and Rutherford (2004) found no significant relationship between perceived cultural cost and residents' overall support for tourism, which is consistent with the findings of Dyer et al. (2007) and Gursoy et al. (2002) findings. These mixed findings suggest that the concern with loss of traditions and norms may vary across residents and communities.

We argue that natives and non-natives may have different responses to the loss of local traditions and norms. Natives may be deeply attached to the local culture. As a result, loss of local traditions and culture should have a negative effect on natives' satisfaction with tourism. Non-natives, on the other hand, may have a different reaction. First, non-natives usually are not as attached to the local culture as natives. Therefore, loss of traditions and norms should have a weaker effect on the overall satisfaction for non-natives than for natives. Further, non-natives who reject the local culture (e.g., local dialect, traditions and interpersonal rules) may 
have a negative attitude toward it (Berry, 1990, 1997). Therefore, loss of local traditions and norms will cause less dissatisfaction but may also result in satisfaction among non-natives because tourism weakens the culture they consider to be negative. From the above reasoning, we propose the following hypothesis:

Hlc: Perceived loss of traditions and norms will have a negative effect on natives' overall satisfaction with tourism but have a weaker negative effect or a positive effect on non-natives' overall satisfaction with tourism.

\section{Sociocultural development}

Although tourism may result in the loss of traditions and norms, it may also bring positive sociocultural benefits to a community. Examples include preservation and restoration of cultural and historic heritages and positive cultural exchange with the outside world (Liu and Var, 1986; Brunt and Courtney, 1999; Dyer et al., 2003). A number of studies have found that residents generally appreciate the positive sociocultural development brought about by tourism. For example, Yoon et al. (2001) found that residents' perception of cultural impacts (e.g., cultural exchange experiences with tourists) had a positive effect on their support for tourism, which was confirmed by Dyer et al. (2007) and Chen and Hsu (2001). However, this positive relationship may vary between natives and non-natives. Since natives may be attached to the local society and culture, sociocultural development should have a positive effect on their overall satisfaction with tourism. Non-natives, on the other hand, are not expected to be as attached to the local society and culture as natives. Non-natives should have a weaker concern with the development of the local sociocultural system. Further, if non-natives reject the local sociocultural system, they may feel somewhat dissatisfied toward tourism development. Therefore, the following hypothesis is proposed:

H1d: Perceived sociocultural development will have a positive effect on natives' overall satisfaction with tourism but will have a weaker positive effect or a negative effect on non-natives' overall satisfaction with tourism.

The conceptual model with the hypotheses is displayed in Figure 1.

\section{TOURISM DEVELOPMENT IN HUANGSHAN}

Huangshan is a famous tourist destination in Anhui Province, China. Mount Huangshan, the most famous natural attraction in the destination, is considered to be the most beautiful mountain in China. It offers magnificent natural scenery comprised of breathtaking sunrises, numerous granite peaks and rocks and a sea of clouds. Mount Huangshan is a World Heritage site and has been recognized by the United Nations Educational Scientific and Cultural Organization (2009). Huangshan also offers a variety of cultural attractions such as 'Xidi and Hongcun Ancient Villages', 'Tunxi Ancient Street' and 'the Garden of the Bao Family' (Huangshan Travel Information Website 2009). Tourism development in Huangshan dates back to 1979 when Deng Xiaoping visited the area and encouraged tourism development. By the mid-90s, it experienced rapid growth, and by 2002, total tourist arrivals had reached seven million (China Tourism Administration, 2003).

\section{METHODOLOGY}

\section{Data collection}

Data were collected over three days in Huangshan during April 2004. Residents (i.e., non-tourists who reside in Huangshan) were recruited in two ways based on the needs of the sponsoring agency and available resources. First, a street intercept self-administered survey (Babbie, 2008) was conducted on major streets in Huangshan. Members of the survey team approached individuals and asked them if they would be willing to participate in the study. Assistance from the survey staff was available, if needed. A total of 71 valid questionnaires were collected in this way. The refusal rate among the residents was not recorded during the survey, but informal verbal reports from the survey team suggested it was relatively low. Second, adopting Lu's (1996) approach, 250 questionnaires were distributed to parents/ relatives/guardians of students enrolled in three local schools (one primary school and two high schools). A total of 239 valid questionnaires were returned.

In summary, a total of 310 individuals responded to the questionnaire. The results of chi-square analysis revealed that there was no significant difference between the two

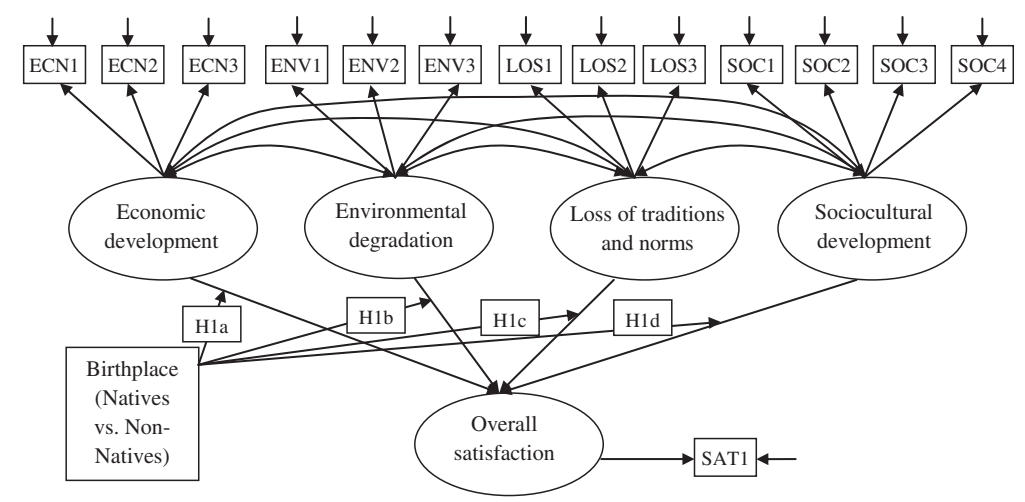

Figure 1. The conceptual model: the effects of perceived tourism impacts on overall satisfaction moderated by birthplace (i.e., natives versus non-natives) $\left(N_{\text {natives }}=216 ; N_{\text {non-natives }}=91\right)$. 
survey locations in terms of the proportion of natives and non-natives $(p>0.10)$. Further, in either location, natives (i.e., native-born residents) and non-natives (non-native-born residents) had a similar demographic profile (i.e., gender, age, employment in tourism industry, level of income and level of education; $p>0.10$; Table 1 ). Therefore, it was reasonable to combine the samples from two locations to improve the power of the statistical test (Cohen et al., 2003; Hair et al., 2006). In addition, the orthogonal relationship between birthplace and other demographic variables improved internal validity of the finding because the confounding effects of those demographic variables were ruled out (Shadish et al., 2002; Cohen et al., 2003). It should be noted that the sample in this study may not have been representative of the local population. However, the sample was considered to be acceptable given the exploratory nature of this study (Kruglanski, 1975; Lynch, 1999).

\section{Measurement}

Four types of perceived tourism impacts identified by Dyer et al. (2003), Liu and Var (1986) and Lu (1996)environmental degradation, loss of traditions and norms, sociocultural development and economic developmentwere investigated. Thirteen statements that theoretically represent the four perceived tourism impact dimensions were adapted from Lu's (1996) instrument, which was used in a study of residents in southern Anhui, where Huangshan is located. Environmental degradation was measured with three items: (i) tourism development causes severe soil and water pollution; (ii) tourism development degrades the quality of the local eco-environment; and (iii) tourism development generates a large amount of garbage. Loss of traditions and norms, the second perceived impact dimension, also was measured with three items: (i) tourism development reduces the trust between people; (ii) tourism development undermines local good traditions; and (iii) tourism development lowers moral standards in society. The third perceived tourism impact dimension, sociocultural development, was measured with four items: (i) tourism development accelerates town construction; (ii) tourism development benefits the development of local traditional culture; (iii) tourism development raises the fame of the town; and (iv) tourism development broadens the vision of and improves the thoughts of local residents. And the fourth perceived tourism impact dimension, economic development, was

Table 1. Tests of associations between birthplace and other sociodemographic variables

\begin{tabular}{lcccc}
\hline & \multicolumn{4}{c}{ Tests of association with birthplace } \\
\cline { 2 - 5 } & $N$ & $\chi^{2}(d f)^{*}$ & Mann-Whitney $U^{* *}$ & $p$-value \\
\hline Employment & 305 & $0.150(1)$ & - & $0.698^{\dagger}$ \\
Gender & 295 & $2.265(1)$ & - & $0.132^{\dagger}$ \\
Education & 304 & - & 9230.00 & 0.654 \\
Age & 303 & - & 9107.00 & 0.905 \\
Income & 294 & - & 8153.00 & 0.176 \\
\hline
\end{tabular}

Note: *Pearson chi-square analysis.

**2 Independent Sample Nonparametric Test.

$\dagger$ Yate's correction was applied to $2 \times 2$ tables (Sheskin, 2004). measured with three items: (i) tourism development increases employment opportunities; (ii) tourism development increases my income; and (iii) tourism development stimulates local economic development. Residents' overall satisfaction was measured with a single item: I am satisfied with the current status of tourism development. Respondents were asked to indicate their level of agreement with all the statements using a 5 -point Likert scale ( $1=$ strongly agree, $2=$ agree, $3=$ do not know, $4=$ disagree and $5=$ strongly disagree).

\section{Data analysis}

Multiple-group analysis in structural equation modeling was used to test the difference between natives and non-natives in terms of the impact-satisfaction relationship (i.e., path coefficients of the model). Prior to testing the differences of path coefficients, it was important to ensure that natives and non-natives share the same valid measurement model (i.e., measurement invariance; Anderson and Gerbing, 1988; Byrne, 2001). According to MacCallum et al. (1994) and Byrne (2002), sufficient measurement invariance can be achieved by factor loading invariance. Therefore, two steps of analyses were performed to test the factor loading invariance across the two groups (Byrne et al., 1989). First, a configural invariance model was estimated, in which the basic factor structure was fixed as the same across the two groups. The factor loadings, factor variances and covariances, and error variances and covariances, however, were freely estimated for each group. The goodness-of-fit statistics of the configural invariance model indicated how well the same factor structure fit the two groups (i.e., configural invariance). Convergent validity, construct reliability and discriminant validity was also assessed for each group. In the second step, a factor loading invariance model was estimated, which was the same as the configural invariance model except that the factor loadings were constrained to be equal across the two groups (i.e., equality constraints). The chi-square difference between the factor loading invariance model and the configural invariance model was then used to assess factor loading invariance.

After ensuring the measurement invariance, the path coefficient invariance was examined between natives and non-natives. An overall invariance of path coefficients across groups was tested to control for type I error (Bollen, 1989; Cohen et al., 2003). The overall invariance of path coefficients was tested in two steps. First, a baseline model was estimated in which all the path coefficients were freely estimated for the two groups. Second, a constrained model was estimated, in which all the path coefficients were constrained to be equal across the two groups. The chi-square difference between the two models was then referenced to assess the overall path coefficients invariance. In situations where the chi-square difference for the overall test was significant, the equality constraint was put on each individual path coefficient to find out the one(s) that vary across groups. Given the exploratory nature of the study, the level of statistical significance was set as $\alpha=0.10$ during the test of the differences between natives' and non-natives' impactsatisfaction relationship (Gall et al., 1996; Morgan et al., 2011). 


\section{RESULTS}

\section{Sample characteristics and descriptive statistics}

Respondents' socio-demographic characteristics are reported in Table 2. The majority of respondents were native born, were between 19 and 50 years old, and had a high school or lower level of education. Only a small number of respondents had a monthly income higher than 2000 RMB. There was a similar percentage of women and men and of people who were and were not employed in the tourism industry (Table 2). In addition, natives and non-natives perceived a similar level of tourism impacts associated with local tourism development ( $p>0.10$; Table 3$)$.

\section{Testing of measurement invariance between natives and non-natives}

The configural invariance model achieved a good fit $\left(\chi^{2}(136)=212.694(p<0.01), \chi^{2} / d f=1.56\right.$; root mean square error of approximation $=0.058$, comparative fit index $=$ 0.953, non-normed fit index $=0.937$ ) (Carmines and McIver, 1981; Bentler, 1992; Browne and Cudeck, 1993; Kaplan, 2000), indicating that natives and non-natives shared the same factor structure. For each group, the measurement model had well-established convergent validity, construct reliability and discriminant validity. All the factor loadings were statistically significant with a $t$-value of 3.29 or higher (Table 4). Therefore, the convergent validity of the measurement model was deemed to be secure (Hair et al., 2006). The

Table 2. Respondents' socio-demographic characteristics

\begin{tabular}{|c|c|c|}
\hline & $n$ & $\%$ \\
\hline \multicolumn{3}{|l|}{ Gender $(N=293)$} \\
\hline Female & 136 & 46.4 \\
\hline Male & 157 & 53.6 \\
\hline \multicolumn{3}{|l|}{ Age (years) $(N=300)$} \\
\hline Below 18 & 6 & 2.0 \\
\hline $19-30$ & 50 & 16.7 \\
\hline $31-40$ & 176 & 58.7 \\
\hline $41-50$ & 61 & 20.3 \\
\hline $51-60$ & 4 & 1.3 \\
\hline Above 60 & 3 & 1.0 \\
\hline \multicolumn{3}{|c|}{ Employed in tourism industry $(N=306)$} \\
\hline Yes & 135 & 44.1 \\
\hline No & 171 & 55.9 \\
\hline \multicolumn{3}{|l|}{ Monthly income $(N=295)$} \\
\hline Below 300RMB & 31 & 10.5 \\
\hline $301 \mathrm{RMB}$ to $600 \mathrm{RMB}$ & 76 & 25.8 \\
\hline $601 \mathrm{RMB}$ to $800 \mathrm{RMB}$ & 40 & 13.6 \\
\hline $801 \mathrm{RMB}$ to $1000 \mathrm{RMB}$ & 53 & 18.0 \\
\hline $1001 \mathrm{RMB}$ to $1500 \mathrm{RMB}$ & 67 & 22.7 \\
\hline $1501 \mathrm{RMB}$ to $2000 \mathrm{RMB}$ & 18 & 6.1 \\
\hline Above 2000RMB & 10 & 3.4 \\
\hline \multicolumn{3}{|l|}{ Birthplace $(N=307)$} \\
\hline Native & 216 & 70.4 \\
\hline Non-native & 91 & 29.6 \\
\hline \multicolumn{3}{|l|}{ Education $(N=306)$} \\
\hline Junior school or below & 110 & 35.9 \\
\hline High School & 123 & 40.2 \\
\hline 3-year college degree & 50 & 16.3 \\
\hline 4-year college degree or higher & 23 & 7.5 \\
\hline
\end{tabular}

construct reliability ${ }^{1}$ of the four latent constructs was between 0.65 and 0.90 for both natives and non-natives, which indicated a good or acceptable level of construct reliability (Hair et al., 2006). In addition, the variance-extracted percentages $^{2}$ for the four latent constructs all exceeded their maximum squared between-construct correlations. This result indicated that the discriminant validity of the model was established (Fornell and Larcker, 1981).

After the factor loadings were constrained to be equal between the two groups (i.e., factor loading invariance model), the model fit remained similar $\left(\chi^{2}(145)=216.865(p<0.01)\right.$, $\chi^{2} / d f=1.50$; root mean square error of approximation $=0.053$, comparative fit index $=0.956$, non-normed fit index $=0.945$ ) with a non-significant chi-square change $\left(\Delta \chi^{2}(9)=4.171\right.$; $p>0.50$; Table 5). This indicated that the measurement invariance was tenable and the test of path coefficients invariance appropriate.

Testing the path coefficients invariance between natives and non-natives

Table 6 reports the results of testing the path coefficients invariance. A significant chi-square change was observed $\left(\Delta \chi^{2}(4)=9.937 ; p<0.05\right)$ after all the path coefficients were constrained to be equal between natives and non-natives, Thus, there was an overall difference between natives and non-natives in terms of the impact-satisfaction relationship, and H1 was supported. Application of equality constraint on individual path coefficients revealed that the effects of environmental degradation and loss of traditions and norms on satisfaction were significantly different between natives and non-natives (Table 7 and Figure 2). For non-natives, environmental degradation had a significant negative effect on satisfaction $(b=-0.309, p<0.01)$, which was contrasted with a non-significant negative effect among natives $(b=-0.071, p>0.10)$. Therefore, the direction of differences between natives and non-natives was opposite to what was specified in H1b. Loss of traditions and norms had a significant negative effect on natives' satisfaction $(b=-0.329$, $p<0.05$ ), but a significant positive effect on non-natives' satisfaction $(b=0.406, p<0.05)$. Therefore, H1c was supported. The effects of economic development and sociocultural development were not statistically significant between the two groups in multiple-group analysis. Therefore, H1a and H1d were not supported. However, individual path coefficients did reveal potential group differences in the hypothesized direction. For example, economic development had a non-significant effect on natives' satisfaction $(b=0.247, p>0.10)$ but a significant positive effect on non-natives' satisfaction $(b=0.453, p<0.10)$. Sociocultural development had a non-significant positive effect on satisfaction among natives $(b=0.163, p>0.10)$ but a non-significant negative effect among non-natives $(b=-0.178, p>0.10)$. In addition, the multiple squared correlation of satisfaction was

${ }^{1}$ Construct reliability is calculated using the formula $\mathrm{CR}=(\Sigma \lambda)^{2} /\left[(\Sigma \lambda)^{2}+\Sigma \delta\right]$, where $\lambda$ is the factor loading and $\delta$ the item error variance (Hair et al., 2006). ${ }^{2}$ Variance-extracted percentage is calculated using the formula $\mathrm{VE}=\Sigma \lambda^{2} / n$, where $\lambda$ is the factor loading and $n$ the number of indicators in a latent construct (Fornell and Larcker, 1981). 
Table 3. Perceived tourism impacts and overall satisfaction: natives versus non-natives $\left(N_{\text {natives }}=216 ; N_{\text {non-natives }}=91\right)$

\begin{tabular}{|c|c|c|c|c|c|}
\hline \multirow[b]{2}{*}{ Item (tourism development) } & \multicolumn{2}{|c|}{ Natives } & \multicolumn{2}{|c|}{ Non-Natives } & \multirow[b]{2}{*}{$p^{*}$} \\
\hline & $M$ & $S D$ & $M$ & $S D$ & \\
\hline \multicolumn{6}{|l|}{ Economic development } \\
\hline Increases employment opportunities & 4.11 & 0.73 & 4.23 & 0.68 & 0.184 \\
\hline Increases my income & 3.60 & 1.00 & 3.64 & 1.03 & 0.778 \\
\hline Stimulates local economic development & 4.35 & 0.69 & 4.41 & 0.61 & 0.479 \\
\hline \multicolumn{6}{|l|}{ Environmental degradation } \\
\hline Causes severe soil and water pollution & 3.06 & 1.14 & 3.16 & 1.26 & 0.498 \\
\hline Degrades the quality of the local eco-environment & 2.94 & 1.11 & 3.15 & 1.21 & 0.126 \\
\hline Generates a large amount of garbage & 3.19 & 1.13 & 3.24 & 1.19 & 0.741 \\
\hline \multicolumn{6}{|l|}{ Loss of traditions and norms } \\
\hline Reduces the trust between people & 3.03 & 1.05 & 2.82 & 1.09 & 0.126 \\
\hline Undermines local good traditions & 2.85 & 0.97 & 2.88 & 1.08 & 0.800 \\
\hline Lowers moral standards in society & 2.62 & 0.98 & 2.52 & 1.02 & 0.424 \\
\hline \multicolumn{6}{|l|}{ Sociocultural development } \\
\hline Accelerates town construction & 4.21 & 0.65 & 4.26 & 0.59 & 0.486 \\
\hline Benefits the development of local traditional culture & 4.05 & 0.65 & 4.11 & 0.75 & 0.454 \\
\hline Raises the fame of the town & 4.29 & 0.65 & 4.36 & 0.62 & 0.377 \\
\hline $\begin{array}{l}\text { Broadens the vision of and improves the thoughts of local residents } \\
\text { Overall satisfaction }\end{array}$ & 3.87 & 0.74 & 3.90 & 0.86 & 0.752 \\
\hline I am satisfied with the current status of tourism development & 3.31 & 1.05 & 3.35 & 0.99 & 0.775 \\
\hline
\end{tabular}

Note: Significance of the results of the independent sample $T$-test between natives and non-natives. Scale: $1=$ strongly agree; $5=$ strongly disagree.

Table 4. Completely standardized factor loadings: natives versus non-natives $\left(N_{\text {natives }}=216 ; N_{\text {non-natives }}=91\right)$

\begin{tabular}{|c|c|c|}
\hline Item (tourism development) & Natives & $\begin{array}{l}\text { Non- } \\
\text { natives }\end{array}$ \\
\hline \multicolumn{3}{|l|}{ Economic development (ECN) } \\
\hline ECN1: increases employment opportunities & 0.788 & 0.760 \\
\hline ECN2: increases my income & 0.632 & 0.451 \\
\hline $\begin{array}{l}\text { ECN3: stimulates local economic development } \\
\text { Environmental degradation (ENV) }\end{array}$ & 0.509 & 0.670 \\
\hline ENV1: causes severe soil and water pollution & 0.905 & 0.844 \\
\hline $\begin{array}{l}\text { ENV2: degrades the quality of the local } \\
\text { eco-environment }\end{array}$ & 0.882 & 0.834 \\
\hline $\begin{array}{l}\text { ENV3: generates a large amount of garbage } \\
\text { Loss of traditions and norms (LOS) }\end{array}$ & 0.699 & 0.773 \\
\hline LOS1: reduces the trust between people & 0.643 & 0.511 \\
\hline LOS2: undermines local good traditions & 0.813 & 0.816 \\
\hline $\begin{array}{l}\text { LOS3: lowers moral standards in society } \\
\text { Sociocultural development (SOC) }\end{array}$ & 0.727 & 0.699 \\
\hline SOC1: accelerates town construction & 0.454 & 0.617 \\
\hline $\begin{array}{l}\text { SOC2: benefits the development of local } \\
\text { traditional culture }\end{array}$ & 0.691 & 0.731 \\
\hline SOC3: raises the fame of the town & 0.611 & 0.646 \\
\hline $\begin{array}{l}\text { SOC4: broadens the vision of and improves } \\
\text { the thoughts of local residents }\end{array}$ & 0.577 & 0.631 \\
\hline
\end{tabular}

Table 5. Test of measurement invariance between natives and nonnatives $\left(N_{\text {natives }}=216 ; N_{\text {non-natives }}=91\right)$

\begin{tabular}{lcc}
\hline & $\begin{array}{c}\text { Configural } \\
\text { invariance model }\end{array}$ & $\begin{array}{c}\text { Factor loading } \\
\text { invariance model }\end{array}$ \\
\hline$\chi^{2}(d f)$ & $212.694(136)$ & $216.865(145)$ \\
Comparative fit index & 0.953 & 0.956 \\
Rho & 0.937 & 0.945 \\
Root mean square error of & 0.058 & 0.053 \\
approximation & & \\
$\Delta \chi^{2}(\Delta d f)$ & $4.171(9)$ & \\
$p$-value of $\Delta \chi^{2}(\Delta d f)$ & 0.900 & \\
\hline
\end{tabular}

Table 6. Test of path coefficients invariance between natives and non-natives $\left(N_{\text {natives }}=216 ; N_{\text {non-natives }}=91\right)$

\begin{tabular}{lccccc}
\hline Model & $\chi^{2}$ & $d f$ & $\Delta \chi^{2}$ & $\Delta d f$ & $p$ \\
\hline Baseline model & 216.865 & 145 & - & - & - \\
$\begin{array}{l}\text { Constrained model } \\
\text { ECN-SAT constrained }\end{array}$ & 226.802 & 149 & 9.937 & 4 & $0.042^{* *}$ \\
model & & 146 & 0.375 & 1 & 0.540 \\
$\begin{array}{l}\text { ENV-SAT constrained } \\
\text { model }\end{array}$ & 219.720 & 146 & 2.855 & 1 & $0.091^{*}$ \\
$\begin{array}{l}\text { LOS-SAT constrained } \\
\text { model }\end{array}$ & 225.369 & 146 & 8.504 & 1 & $0.001^{* * *}$ \\
$\begin{array}{l}\text { SOC-SAT constrained } \\
\text { model }\end{array}$ & 217.232 & 146 & 0.367 & 1 & 0.545 \\
\hline
\end{tabular}

*Note: $p<0.10 ; * * p<0.05 ; * * * p<0.01$.

ECN, economic development; ENV, environmental degradation; LOS, loss of traditions and norms; SOC, sociocultural development; SAT, satisfaction.

0.108 for natives and 0.154 for non-natives, indicating that the model explained a significant portion of variance for each group (Table 7).

\section{DISCUSSION}

The relationship between perceived tourism impacts and overall satisfaction with tourism varied between natives and non-natives. Loss of traditions and norms had a significant negative effect on natives' satisfaction possibly because natives are attached to their local culture (Sheldon and Var, 1984; Um and Crompton, 1987). For non-natives, however, the loss of traditions and norms had a significant positive effect on satisfaction with tourism development. This may be explained as follows. In this study, non-natives may not have been well acculturated into the local society (Berry, 1990, 1997) and therefore held a somewhat negative perception 
Table 7. Path coefficients for natives and non-natives $\left(N_{\text {natives }}=216 ; N_{\text {non-natives }}=91\right)$

\begin{tabular}{llccrrr}
\hline Group & Solution & ECN-SAT & ENV-SAT & LOS-SAT & SOC-SAT & SMC \\
\hline Native & Standardized & 0.136 & -0.070 & $-0.201^{* *}$ & 0.047 \\
& Unstandardized & 0.247 & -0.071 & $-0.329^{* *}$ & 0.163 \\
Non-native & Standardized & $0.248^{*}$ & $-0.339^{* * *}$ & $0.266^{* *}$ & -0.063 \\
& Unstandardized & $0.453^{*}$ & $-0.309^{* * *}$ & $0.406^{* *}$ & -0.178 & 0.154 \\
& & &
\end{tabular}

Note: The italicized coefficients were significantly different in multiple-group analysis.

ECN, economic development; ENV, environmental degradation; LOS, loss of traditions and norms; SOC, sociocultural development; SAT, satisfaction; SMC, squared multiple correlation.

$* p<0.10 ; * * p<0.05 ; * * * p<0.01$.

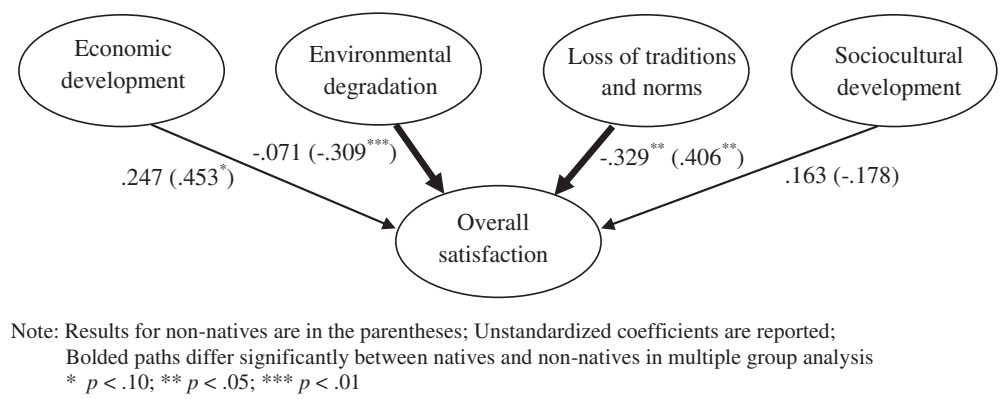

Figure 2. The effects of perceived tourism impacts on overall satisfaction: natives versus non-natives $\left(N_{\text {natives }}=216 ; N_{\text {non-natives }}=91\right)$.

of local traditions and norms. As a result, the loss of those traditions and norms increased their satisfaction with tourism development.

Perceived economic development did not have a significant effect on natives' satisfaction but had a significant positive effect on non-natives' satisfaction. Non-natives' concern with economic development may be attributed to their psychological insecurity. Non-natives may be less familiar with the local community, have a smaller social network and be less psychologically secure than natives (Suh and Lee, 2006). In response, non-natives try to offset their psychological insecurity with financial security (Rocha et al., 2006). In this study, nonnatives' response was likely manifested through greater concern with economic development.

With respect to the effect of environmental degradation, the result was contrary to the hypothesis. Non-natives rather than natives attached more importance to environmental degradation when evaluating the tourism development. This difference may be explained as follows. Huangshan is a tourist destination with an amiable natural environment. Many non-natives may have originally resided in areas with worse ecological conditions. As a result, non-natives likely had a stronger environmental protection mindset than natives. Further, natives may not be aware of the importance of environment, especially if environmental degradation has not been a problem (Tremblay and Dunlap, 1978).

\section{CONCLUSIONS, LIMITATION AND IMPLICATION}

Using a sample of residents in Huangshan, China, we found that natives' and non-natives' satisfaction with tourism were affected by tourism impacts, but in different ways. First, environmental degradation negatively affected non-natives' (not natives') level of satisfaction. Second, loss of traditions and norms had a negative effect on natives' satisfaction but a positive effect on non-natives' satisfaction.

The results of this study showed that the impact-satisfaction relationship varied between different groups in a community (e.g., natives versus non-natives). Therefore, researchers must account for the heterogeneity of residents when interpreting the effect of tourism impacts. As shown in this study, multiplegroup analysis is a useful approach to examine the potential heterogeneity of residents. In addition, natives and non-natives differed in their responses to environmental degradation and loss of traditions and norms. Thus, these two impacts deserve extra attention in the future by researchers who study natives and non-natives in the local community. Finally, we utilized acculturation and place attachment theories and literature to explain the differences between natives and non-natives. In the future, researchers may consider incorporating these two factors in their theoretical frameworks.

Although the overall findings of this study contribute to the literature, we do recognize that this study had limitations. First, the sample of this study was not very representative of the local population, but to some extent biased toward families with children at schools. Second, the non-native sample was relatively small $(N=91)$. This may have limited the statistical power to some degree. Third, residents' overall satisfaction was a single-item construct, which did not control well for measurement error (Churchill, 1979). Therefore, future research should validate the findings of this study by using a larger and more representative sample and a more reliable measurement of satisfaction. Fourth, this study defined natives as individuals who were born in the local community. However, it is possible that some native-born residents did not grow up in the local community, making them less 'native'. Therefore, future research may consider accounting for the number of years residents have spent in the local community when defining or operationalizing 'natives'. Researchers may 
also want to examine the potential differences between nativeborn residents who grew up and who did not grow up in the local community. Fifth, this study only investigated the natives and non-natives in one community. Previous studies show that residents' attitude toward tourism development may be contextual. In other words, some differences between the natives and non-natives identified in this study may not be evident in other destination communities with different conditions. For example, non-natives in a different community may evaluate tourism development in a way similar to natives if non-natives are well acculturated into the local society. Therefore, it is desirable to investigate the differences between natives and non-natives in different types of communities.

From a practical perspective, tourism planners and policy makers should consider and address the potential differences between natives and non-natives to ensure their satisfaction with development. For example, if tourism development has the potential to result in a loss of local culture, tourism planners should try to involve natives in the development of cultural preservation plans and communicating the positive benefits brought about by tourism development. Alternatively, for non-natives who may resent the local culture, tourism planners should introduce education programs to improve their appreciation of the local culture. Further, tourism planners should pay attention to the potential neglect of negative environmental impacts among natives and promote environmental education for this group if necessary. Since natives often account for a large proportion of the local population, their apathy about the environment and/or environmentally unfriendly practices in tourism industry will not only make non-natives unhappy but also undermine the sustainability of local tourism development.

To execute the aforementioned strategies effectively and efficiently, tourism planners need to know the size and geographic distribution of natives and non-natives in the local community. In addition, tourism planners need to understand the origin of the non-natives. Non-natives who migrated from places that are culturally and geographically distant to the local community may be quite different from natives in terms of their response to tourism impacts. However, non-natives coming from places that are culturally and geographically close to the local community may only show limited differences from natives.

\section{REFERENCES}

Aaker J, Schmitt B. 2001. Culture-dependent assimilation and differentiation of the self. Journal of Cross Cultural Psychology 32(5): 561-576.

Altman I, Chemers MM. 1984. Culture and Environment. Cambridge University Press: New York.

Andereck KL. 1995. Environmental consequences of tourism: a review of recent research. In Linking Tourism, the Environment, and Sustainability. Annual Meeting of the National Recreation and Park Association, General Technical Report No. INTGTR-323; 77-81.

Andereck KL, Vogt, CA. 2000. The relationship between residents' attitudes toward tourism and tourism development options. Journal of Travel Research 39(1): 27-36.
Andereck KL, Valentine KM, Knopf RC, Vogt CA. 2005. Residents' perceptions of community tourism impacts. Annals of Tourism Research 32(4): 1056-1076.

Anderson JC, Gerbing DW. 1988. Structural equation modeling in practice: a review and recommended two-step approach. Psychological Bulletin 103(3): 411-423.

Babbie ER. 2008. The Basic of Social Research. 4th edn. Thomson/ Wadsworth: Belmont, CA.

Bentler P. 1992. On the fit of models to covariance and methodology. Psychological Bulletin 112(3): 400-404.

Berry JW. 1990. Psychology of acculturation. In Nebraska Symposium on Motivation, 1989: Cross-Cultural Perspectives, Berman J (ed). Nebraska University Press: Lincoln, NE; 201-234.

Berry JW. 1997. Immigration, acculturation, and adaptation. Applied Psychology: An International Review 46(1): 5-68.

Berry JW, Trimble JE, Olmedo EL. 1986. Assessment of acculturation. In Field Methods in Cross-Cultural Research, Lonner WJ, Berry JW (eds). Sage: Newbury Park, CA; 291-324.

Bollen KA. 1989. Structural Equations with Latent Variables. John Wiley \& Sons, Inc.: New York.

Browne MW, Cudeck R. 1993. Alternative ways of assessing model fit. In Testing Structural Equation Models, Bollen KA, Long JS (eds). Sage: Newbury Park, CA; 136-162.

Brunt P, Courtney P. 1999. Host perceptions of sociocultural impacts. Annals of Tourism Research 26(3): 493-515.

Byrd ET, Bosley HE, Dronberger, MG. 2009. Comparisons of stakeholder perceptions of tourism impacts in rural eastern North Carolina. Tourism Management 30(5): 693-703.

Byrne BM. 2001. Structural Equation Modeling with AMOS: Basics Concepts, Applications, and Programming. Lawrence Erlbaum: Mahwah, NJ.

Byrne BM. 2002. Measurement equivalence: a comparison of methods based on confirmatory factor analysis and item response theory. Journal of Applied Psychology 87(3): 517-529.

Byrne BM, Shavelson RJ, Muthèn B. 1989. Testing for the equivalence of factor covariance and mean structures: the issue of partial measurement invariance. Psychological Bulletin 105(3): 456-466.

Cai F, Wang D. 2008. Impacts of internal migration on economic growth and urban development in China. In Migration and Development within and across Borders: Research and Policy Perspectives on Internal and International Migration, Dewind J, Holdaway J (eds). SSRC: New York; 245-272.

Carmines E, McIver J. 1981. Analyzing models with unobserved variables: analysis of covariance structure. In Social Measurement: Current Issues, Bohrnstedt G, Borgatta E (eds). Sage: Beverly Hill, CA; 65-115.

Catalano R. 1991. The health effects of economic insecurity. American Journal of Public Health 81: 1148-1152.

Chen JS, Hsu CHC. 2001. Developing and validating a riverboat gaming impact scale. Annals of Tourism Research 28(2): 459-476.

China Tourism Administration (CNTA). 2003. 2003 Yearbook of China Tourism Statistics. China Tourism Press: Beijing.

Churchill GA, Jr. 1979. A paradigm for developing better measures of marketing constructs. Journal of Marketing Research 16(1): 64-73.

Cohen J, Cohen P, West SG, Aiken LS. 2003. Applied Multiple Regression/Correlation Analysis for the Behavioral Sciences. 3rd edn. Lawrence Erlbaum: Mahwah, NJ.

Cottrell S, Vaske JJ, Shen F. 2005. Predictors of sustainable tourism: resident perceptions of tourism in Holland and China. In Proceedings of the 2005 Northeastern Recreation Research Symposium, Bolton Landing, NY, Peden JG, Schuster RM (eds). US Forest Service, Northeastern Research Station: Newtown Square, PA; 337-344.

Devine-Wright P, Howes Y. 2010. Disruption to place attachment and the protection of restorative environments: a wind energy case study. Journal of Environmental Psychology 30(3): 271-280.

Doğan HZ. 1989. Forms of adjustment: sociocultural impacts of tourism. Annals of Tourism Research 16(2): 216-236. 
Dyer P, Aberdeen L, Schuler S. 2003. Tourism impacts on an Australian indigenous community: a Djabugay case study. Tourism Management 24(1): 83-95.

Dyer P, Gursoy D, Sharma B, Carter J. 2007. Structural modeling of resident perceptions of tourism and associated development on the sunshine coast, Australia. Tourism Management 28(2): 409-422.

Fornell C, Larcker DF. 1981. Evaluating structural equation models with unobservable variables and measurement error. Journal of Marketing Research 18(1): 39-50.

Gall MD, Borg WR, Gall JP. 1996. Education Research: An Introduction. 6th edn. Longman Publishers: White Plains, NY.

Gursoy D, Rutherford, DG. 2004. Host attitudes toward tourism: an improved structural model. Annals of Tourism Research 31(3): $495-516$

Gursoy D, Jurowski C, Uysal M. 2002. Resident attitudes: a structural modeling approach. Annals of Tourism Research 29(1): 79-105.

Hair JF, Black WC, Babin BJ, Anderson RE, Tatham RL. 2006. Multivariate Data Analysis. 6th edn. Pearson Education: Upper Saddle River, NJ.

Haralambopoulos N, Pizam A. 1996. Perceived impacts of tourism: the case of Samos. Annals of Tourism Research 23(3): 503-526.

Hernández B, Hidalgo MC, Salazar-Laplace ME, Hess S. 2007. Place attachment and place identity in natives and non-natives. Journal of Environmental Psychology 27: 310-319.

Hofstede G. 2001. Culture's Consequences: Comparing Values, Behaviors, Institutions, and Organizations across Nations. 2nd edn. Sage Publications, Inc.: Thousand Oaks, CA.

Huangshan Travel Information Website. 2009. http://www.intohuangshan.com/ (accessed 11 July 2009).

Johnson JD, Snepenger DJ, Akis S. 1994. Residents' perceptions of tourism development. Annals of Tourism Research 21(3): 629-642.

Kaplan D. 2000. Structural Equation Modeling: Foundations and Extensions. Sage Publications: Newbury Park, CA.

Kousis M. 1989. Tourism and the family in a rural Cretan community. Annals of Tourism Research 16(3): 318-332.

Kruglanski A. 1975. The two meanings of external validity. Human Relations 28: 653-659.

Lankford SV, Howard DR. 1994. Developing a tourism impact scale. Annals of Tourism Research 21(1): 121-139.

Liu J, Var T. 1986. Resident attitudes towards tourism impacts in Hawaii. Annals of Tourism Research 13(2): 193-214.

Low SM, Altman I. 1992. Place attachment: a conceptual inquiry. In Place Attachment, Altman I, Low SM (eds). Plenum Press: New York; $1-13$.

Lu L. 1996. A study on the attitudes of residents toward tourism development-a case study in South Anhui Tourist Region. Journal of Natural Resources 11(4): 377-382.

Lynch JG. 1999. Theory and external validity. Journal of the Academy of Marketing Science 27(3): 367-376.

MacCallum R, Rosnowski M, Mar CM, Reith JV. 1994. Alternative strategies for cross-validation of covariance structure models. Multivariate Behavioral Research 29(1): 1-32.

Mok C, Slater B, Cheung V. 1991. Residents' attitudes towards tourism in Hong Kong. Journal of Hospitality Management 10(3): 289-293.
Morgan GA, Leech NL, Gloeckner GW, Barrett KC. 2011. IBM SPSS for Introductory Statistics Use and Interpretation. 4th edn. New York: Taylor \& Francis.

Perdue RR, Long PT, Allen L. 1987. Rural resident tourism perceptions and attitudes. Annals of Tourism Research 14(1): 420-429.

Perdue RR, Long PT, Allen L. 1990. Resident support for tourism development. Annals of Tourism Research 17(4): 586-599.

Phinney JS. 1990. Ethnic identity in adolescents and adults: review of research. Psychological Bulletin 108(3): 499-514.

Pizam A, Pokela J. 1985. The perceived impacts of casino gambling on a community. Annals of Tourism Research 12(2): 147-165.

Rocha C, Crowell JH, McCarter AK. 2006. The effects of prolonged job insecurity on the psychological well-being of workers. Journal of Sociology \& Social Welfare 33: 9-28.

Rogler LH. 1994. International migrations: a framework for directing research. American Psychologist 49(8): 701-708.

Scannell L, Gifford R. 2010. The relations between natural and civic place attachment and pro-environmental behavior. Journal of Environmental Psychology 30(3): 289-297.

Shadish WR, Cook TD, Campbell DT. 2002. Experimental and Quasi-experimental Designs for Generalized Causal Inference. Houghton Mifflin Company: New York.

Sheldon PJ, Var T. 1984. Resident attitudes to tourism in North Wales. Tourism Management 5(2): 40-47.

Shen F, Cottrell SP. 2008. A sustainable tourism framework for monitoring residents' satisfaction with agritourism in Chongdugou Village, China. International Journal of Tourism Policy 1(4): 368-375.

Sheskin DJ. 2004. Handbook of Parametric and Nonparametric Statistical Procedures. Chapman \& Hall/CRC: Boca Raton, FL.

Smith PB, Bond MH. 1999. Social Psychology across Cultures. 2nd edn. Allyn \& Bacon: Needham Heights.

Spencer DM. 2010. Facilitating public participation in tourism planning on American Indian reservations: a case study involving the nominal group technique. Tourism Management 31(5): 684-690.

Suh S, Lee M-S. 2006. Group work for Korean expatriate women in the United States. Journal for Specialists in Group Work 31(4): 353-369

Tosun C. 2002. Host perceptions of impacts: a comparative tourism study. Annals of Tourism Research 29(1): 231-253.

Tremblay KR, Dunlap RR. 1978. Rural-urban residence and concern with environmental quality: a replication and extension. Rural Sociology 43(3): 474-491.

Um S, Crompton JL. 1987. Measuring resident's attachment levels in a host community. Journal of Travel Research 26(1): 27-29.

United Nations Educational Scientific and Cultural Organization (UNESCO). 2009. http://portal.unesco.org/en/ev.php-URL_ID $=29008 \&$ URL_DO=DO_TOPIC\&URL_SECTION=201.html. (accessed 19 June 2009).

Williams DR, Patterson ME, Roggenbuck JR, Watson AE. 1992. The variability of user-based social impact standards for wilderness management. Forest Science 14: 29-46.

Yoon T, Gursoy D, Chen JS. 2001. Validating a tourism development theory with structural equation modeling. Tourism Management 22(4): 363-372.

Zimmermann L, Zimmermann KF, Constant A. 2007. Ethnic selfidentification of first-generation immigrants. International Migration Review 41(3): 769-781. 